\title{
What Is the Purpose of the Embryonic Heart Beat? or How Facts Can Ultimately Prevail over Physiological Dogma
}

\author{
Warren W. Burggren ${ }^{\star}$ \\ Department of Biological Sciences, University of North \\ Texas, Denton, Texas 76205
}

Accepted 4/19/04

\section{ABSTRACT}

Embryonic physiology is often viewed as merely those processes understood for the adult but conducted on a smaller physical scale. Yet striking examples of the inaccuracy of this perspective can be identified in the embryonic cardiovascular system. For example, dogma holds that the embryonic heart begins to beat to pump blood for convective transport, just like that of the adult. This is the major assumption inherent in the hypothesis we have called "convective synchronotropy"; that is, the embryonic heart starts to beat synchronously with the need for convective blood flow. However, there is compelling evidence on many fronts that the convective flow of blood generated by the early embryonic vertebrate heart is simply not required for transport of oxygen, nutrients, metabolic wastes, or hormones, all of which can be achieved entirely by diffusion. In fact, fish, amphibian, and bird embryos lacking a functional heart (either through surgical intervention or mutation) or whose oxygenhemoglobin transport has been chemically eliminated nonetheless continue to function and grow in size for extended periods up to the point at which diffusion alone can no longer serve oxygen transport needs. We advocate the alternative hypothesis of "prosynchronotropy" (i.e., the heart starts to beat well before convective blood flow is needed for bulk transport). So, what is the purpose of the early embryonic heart beat? Evidence is presented herein in support of a morphogenic rationale for prosynchronotropy. Specifically, it appears that the initial rationale for the beat of the vertebrate embryonic heart may be two-fold: to aid in subtle but significant aspects of cardiac growth, shaping, and maturation, and to facilitate cardiac maturation angiogenesis-the formation of new vessels by sprouting from vessel tips. Ultimately, the embryonic cardio-

*E-mail: burggren@unt.edu.

Physiological and Biochemical Zoology 77(3):333-345. 2004. (C) 2004 by The University of Chicago. All rights reserved. 1522-2152/2004/7703-3178\$15.00 vascular system provides a graphic demonstration of how adult physiological functions should not, without verification, be interpolated back to the embryo of that species.

\section{Introduction}

That the unfailing beat of the heart is necessary for life is one of the few dogmas that enjoys equal popularity among both cardiovascular physiologists and the lay public. The convective flow of blood through the circulation provides the ceaseless transport of the respiratory gases and nutrients required by metabolism, the waste products produced by metabolism, and the hormonal cues that regulate metabolism and a myriad of other physiological functions. This role of the circulation clearly is indisputable in adult vertebrates. Yet emerging data resulting from the burgeoning interest in developmental physiology are calling into question this most established of physiological (and cultural) dogmas regarding the function of the heart. Indeed, in this article the reader will learn that the strong convective flow of blood clearly evident in early developmental stages is in fact not necessary for short-term growth and development of the embryo.

Given that physiological measurements on adults probably outnumber those on early developmental stages by several thousandfold, why should the reader care about cardiovascular-or any other-physiological processes in these earliest, previously neglected developmental stages? The answers have relevance to both basic and applied research. Evolutionary biologists studying physiological processes have largely focused on evolution as change in a series of adult morphs, by far the most commonly studied form of any species. Yet a more appropriate view of evolution is change in a series of ontogenies, not simply change in a series of adults (or for that matter, change in a series of fertilized eggs, larvae, or juveniles). Thus, understanding the physiologies of immature stages may hold as many or more clues to evolutionary events as the physiologies of the mature stages, especially because natural selection acts aggressively on immature stages (Burggren 1992, 1995).

Understanding the physiology of immature stages has more direct applications as well. The early developmental stages of a wide variety of vertebrate embryos show not only qualitative but also quantitative similarities. For example, the overall level 
of blood pressure, cardiac output, peripheral resistance, and their subsequent rate of increase during the first days of heart beat are all surprisingly similar in the zebra fish (Pelster and Burggren 1996; Hu et al. 2000), Xenopus (Hou and Burggren 1995a, 1995b; Fritsche and Burggren 1996; Territo and Burggren 1998; Warburton and Fritsche 2000), the bullfrog (Pelster and Burggren 1991; Kimmel 1992; Pelster et al. 1993), and the chicken (see reviews by Clark and Hu 1990; Keller 1997). By inference, we are likely to learn about the physiology of early human embryos by studying these and other animal models. Understanding the cardiovascular physiology of early vertebrate embryos will doubtlessly aid in the planning of future therapeutic interventions in situations of abnormal development.

Finally, the conclusions of this article should encourage those developmental physiologists finding themselves in the role of David facing a Goliath (i.e., dogma based on data from adults). Our hope is that by showing that the convective flow of blood is not required in embryos in the short term, then other broadly based physiological assumptions relying strictly on data from adults will not be so unquestioningly incorporated into our emerging understanding of embryonic physiology.

\section{The Conceptual Background: Diffusion versus Convection in Small Animals}

Gas exchange in small animals, whether they be immature forms of larger species or adults of an innately small species, is a complex interplay between exchange by diffusion and convectively assisted transport (Feder and Burggren 1985; Talbot 1992; Wells and Pinder 1996; Rombough and Moroz 1997; Rombough 1998, 2002). To appreciate fully this dynamic interaction, let us briefly consider the advantages and limitations of gas exchange between environment and tissues by diffusion alone.

\section{Gas Exchange by Diffusion}

Diffusion, while energetically free to the animal, is a very slow process for exchanging gases, nutrients, and wastes. Consequently, exchange based solely on bulk exchange by diffusion in the absence of any internal circulation occurs only in relatively small animals with large surface-area-to-volume ratios. Just how large can an animal be and still rely solely on bulk diffusion? Putting it differently, at what size does an animal have to develop an internal circulation to replace bulk diffusion? Taking an oxycentric viewpoint, the theoretical maximum size (radius, $R$ ) of a diffusion-dependent animal depends on three basic variables: (1) the oxygen partial pressure gradient $\left(\Delta \mathrm{PO}_{2}\right)$ between the environment surrounding an animal and the mitochondria within its innermost cells, (2) the animal's $\mathrm{O}_{2}$ consumption $\left(\dot{\mathrm{Mo}}_{2}\right)$, and (3) Krogh's $\mathrm{O}_{2}$ diffusion constant $\left(\mathrm{Ko}_{2}\right)$, which ironically is not a constant as it depends on the permeability of the material forming the $\mathrm{O}_{2}$ diffusion pathway (i.e., chitin, epithelium, endothelium, etc.). The simplest model incorporating these factors considers a hypothetical animal with a spherical body shape. In such a model, radius, $\mathrm{O}_{2}$ gradient, Krogh's diffusion constant, and $\mathrm{O}_{2}$ consumption are related to each other as follows:

$$
R=\sqrt{\frac{\Delta \mathrm{Po}_{2}}{(1 / 6) \times\left(1 / \mathrm{Ko}_{2}\right) \times \dot{\mathrm{Mo}_{2}}}}
$$

Now, assuming a maximal $\Delta \mathrm{Po}_{2}$ of $150 \mathrm{mmHg}$ (i.e., full environmental oxygenation at sea level and nearly complete anoxia reached at a point in the geographic center of the animal), a Krogh's diffusion constant of $0.045 \mu \mathrm{mol} \mathrm{cm}{ }^{-1} \mathrm{~s}^{-1} \mathrm{mmHg}^{-1}$, and an $\dot{M o}_{2}$ of $200 \mu \mathrm{mol} \mathrm{s}{ }^{-1}$ by the hypothetical animal, then this hypothetical animal's maximum radius, $R$, is $0.134 \mathrm{~cm}$. (This value of metabolic rate represents the middle of the range for a variety of poikilotherms at $20^{\circ}-25^{\circ} \mathrm{C}$. Obviously, there is a huge range of actual metabolic rates that could be used for this calculation, giving attendant wide range in calculation of maximum size.) That is, under these conditions of ideal environmental oxygenation and the above stated $\mathrm{O}_{2}$ consumption, the largest that this spherical-shaped animal could be is a little larger than $2 \mathrm{~mm}$ in diameter without having an anoxic core.

Of course, in reality there are many complicating factors, including irregular body shapes and especially boundary layers, that greatly affect bulk diffusion of gas exchange across an animal's body surface (e.g., Feder et al. 1993; Wells 1996; Rombough 1998). Moreover, exposure to even mild environmental hypoxia would reduce the $\mathrm{Po}_{2}$ gradient, reduce the bulk delivery of $\mathrm{O}_{2}$, and potentially lead to an expanded anoxic core. Bulk diffusion models have been developed for distinct species. While it is beyond the scope of this article to describe such models in depth, consider the recent study of Territo and Altimiras (2001), who quantified theoretical bulk $\mathrm{O}_{2}$ diffusion in the torpedo-shaped larvae of the African clawed frog Xenopus laevis. They created a bulk $\mathrm{O}_{2}$ radial diffusion model that treated the larva as a series of adjacent cylinders of different radii. From this model, Territo and Altimiras (2001) were able to predict the developmental stage-specific $\mathrm{Po}_{2}$ gradients needed to prevent an anoxic core as well as the volume of anoxic tissue that would result in progressive levels of environmental hypoxia. This model predicts that as Xenopus tadpoles develop and grow beyond developmental stages NF 50-51, they quickly outstrip $\mathrm{O}_{2}$ delivery supplied by bulk diffusion and must develop a vigorous internal circulation to help support the increasing large body size and mass.

Whatever the model used to predict bulk diffusional $\mathrm{O}_{2}$ delivery, model predictions and extant animal design are very much in agreement with respect to animal size: very few animals lacking internal circulations exceed about $1 \mathrm{~mm}$ in diameter. Some animals without internal convective systems are larger than $1 \mathrm{~mm}$, such as flatworms such as the polyclad worms 
Oligclado or Stylochoplana, that can reach diameters of several centimeters, but their extreme dorsolateral flattening means that the interiormost cells of these plate-shaped worms are in fact never more than $1 \mathrm{~mm}$ from the water surrounding the animal. Similarly, sponges appear to be large metazoans, but their ciliated cells provide an internal convection of sea water through channels (ostia) that, once again, bring sea water to within $<1 \mathrm{~mm}$ of the most internalized cells.

Of course, some animals without internal convective circulations can and do live on the respiratory fringes. Figure 1 relates the hypothetical size of an approximately spherical animal with the $\mathrm{O}_{2}$ consumption that it can support, based on the equation above. From this graph, it becomes apparent that an animal can be larger if it has a lower rate of $\dot{M o}_{2}$ (e.g., a helminth in cool water; Fig. 1, Exception \#1). Alternatively, animals with high metabolic rates (e.g., rotifers in warm water; Fig. 1, Exception \#2) are restricted in their maximum body size.

Embryos of even the largest animals begin as a small collection of a few hundred cells supported entirely by diffusion until a respiratory transition from diffusional to convective transport occurs. But when does the transition occur, and how can we determine it?

\section{The Respiratory Transition from Diffusion to Convection}

All vertebrate embryos must make the transition from gas, nutrient, and waste exchange by diffusion to a mixed diffusiveconvective system to ultimately depending entirely on internal convective transport. Yet for such a ubiquitous physiological transition, few studies from only a handful of laboratories have focused on this phenomenon (e.g., Holeton 1971b; Mellish et al. 1994; Burggren and Territo 1995; Pelster and Burggren 1996; Wells and Pinder 1996; Rombough and Moroz 1997; Rombough 1998; Territo and Burggren 1998; Burggren et al. 2000; Territo and Altimiras 2001; Rombough 2002). Given this relatively austere data set for gas exchange in embryos, it has generally been assumed that heart function in embryos, like that of older stages, is inextricably linked to the presence of and need for internal convective transport. Consequently, the early developmental stages, in which the embryonic tube heart is still organizing itself and not generating significant forward blood ejection (e.g., $<24 \mathrm{~h}$ postfertilization in the zebra fish or $<48 \mathrm{~h}$ of incubation in the chicken), can reasonably be assumed to be completely dependent on diffusional exchange. Within a few short hours following heart formation, however, the presence of a vigorous blood flow coursing unidirectionally through an emerging microvasculature is typically assumed to signal the onset of convective $\mathrm{O}_{2}$ transport (though diffusion is still viewed as of key importance in the peripheral tissues). With the further development of an extensive embryonic and extraembryonic circulation, the absolute need for convective gas, nutrient, and waste transport is taken as a given. Collectively,

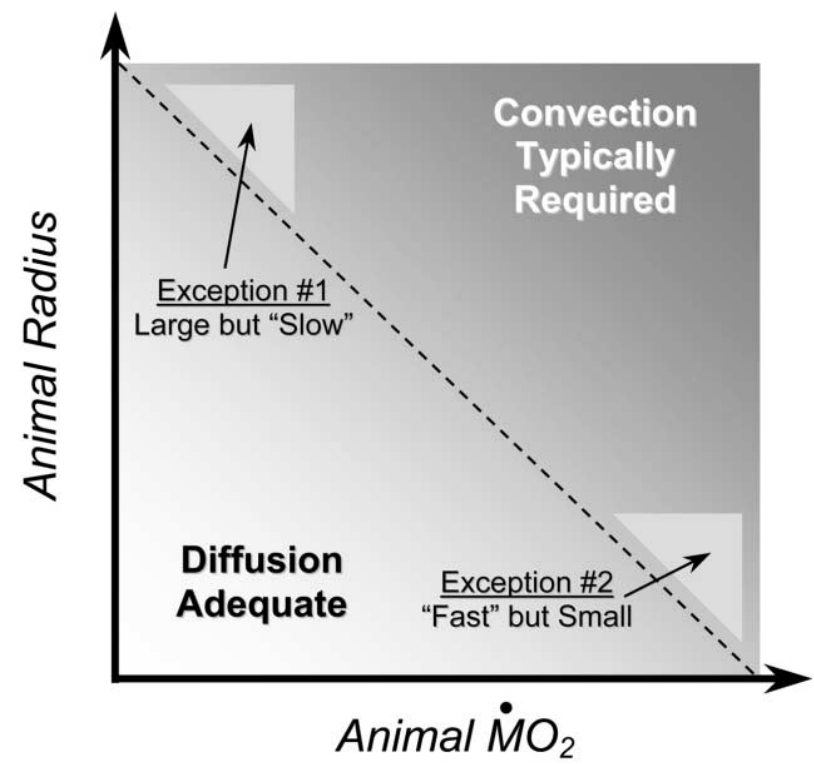

Figure 1. Relationship between radius, $\mathrm{O}_{2}$ consumption, and dependence on convection in a hypothetical animal. As either radius or $\mathrm{O}_{2}$ consumption increases, the ability of diffusion alone to supply the necessary $\mathrm{O}_{2}$ for metabolism declines, necessitating internal convective flow for $\mathrm{O}_{2}$ delivery. Exceptions include animals that can attain larger body sizes because they have only low metabolic rates or animals that can sustain high metabolic rates because body size (and thus diffusion distances) remains small.

these general assumptions can be expressed as hypotheses and tested, as we will now explore.

\section{The Competing Hypotheses}

Two competing hypotheses have been suggested: "synchronotropy" and "prosynchronotropy" (Burggren and Territo 1995; Territo and Burggren 1998; Burggren et al. 2000 for initial discussions of these hypotheses). The purpose of this article is to restate and then update and refine these hypotheses.

Synchronotropy (together, time moving), which for clarification will be renamed "convective synchronotropy," is really a "just in time" hypothesis; that is, convective flow of blood from the heart occurs to ensure that as diffusion falls behind the transport needs of the rapidly growing embryo, convective transport develops just in time to rescue and maintain metabolism (Fig. 2A).

The hypothesis of prosynchronotropy (before synchronotropy) offers the alternative view that the heart begins to beat and consistently eject blood well before the need for convective transport of gases, nutrients, and wastes. That is, the heart begins to create blood flow earlier than is actually required for convective transport, with diffusion still being sufficient for exchange of materials between tissues and external environment (Fig. 2B). As we will explore, this hypothesis can be further 

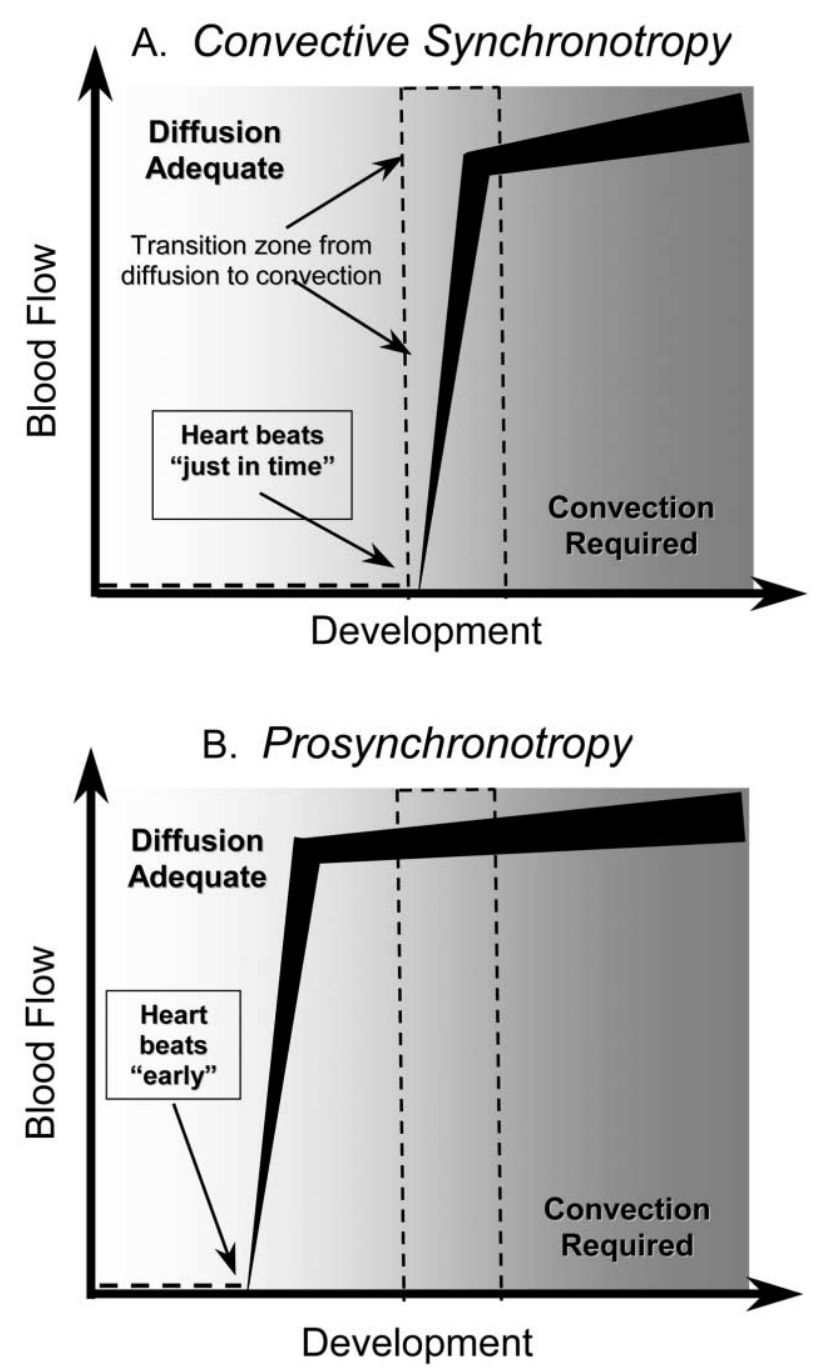

Figure 2. Competing hypotheses of convective synchronotropy and prosynchronotropy. $A$, Convective synchronotropy holds that the heart begins to beat at precisely the point in development when diffusion becomes inadequate for $\mathrm{O}_{2}$ delivery to tissues. $B$, Prosynchronotropy holds that the heart begins to beat well in advance of the point where diffusion must yield to convection. See text for further discussion of these competing hypotheses.

broken down into two subhypotheses: the cardiovascular system begins to function initially for morphogenic purposes, or the cardiovascular system begins to function initially as a simple prelude to future demands, a "dress rehearsal," if you will.

\section{Testing Convective Synchronotropy}

If convective synchronotropy holds, then experimental interruption of the convective transport in the blood of $\mathrm{O}_{2}, \mathrm{CO}_{2}$, or nitrogenous wastes should at the very least undermine growth and development if not prove immediately fatal. To date, two experimental approaches to test this idea have been made: disrupting hemoglobin- $\mathrm{O}_{2}$ transport while maintaining blood flow and reducing or eliminating blood flow altogether.

\section{Disrupting Blood $\mathrm{O}_{2}$ Transport}

In vertebrates $95 \%$ or more of blood $\mathrm{O}_{2}$ transport is achieved by $\mathrm{O}_{2}$ transiently bound to hemoglobin $(\mathrm{Hb})$, with the plasma accounting for only a tiny fraction of bulk $\mathrm{O}_{2}$ transport. Thus, blood $\mathrm{O}_{2}$ transport is highly vulnerable to disruption by either interfering with $\mathrm{Hb}$ function or by destroying the red blood cell itself.

Carbon monoxide competes directly with $\mathrm{O}_{2}$ for binding sites on the hemoglobin molecule. This competition is lopsided: $\mathrm{Hb}-$ CO binding affinity is more than 200 times greater than $\mathrm{Hb}$ $\mathrm{O}_{2}$ binding affinity. In humans, exposures to $\mathrm{CO}$ concentrations of as little as $0.25 \%$ produce unconsciousness after $30 \mathrm{~min}$ of exposure, while values of $>0.4 \%$ produce death within a few minutes. These characteristics of CO make this gas suitable for probing the role of $\mathrm{Hb}-\mathrm{O}_{2}$ transport in embryos, larvae, or any other stage or animal. First, concentrations of $\mathrm{CO}$ that block blood $\mathrm{Hb}-\mathrm{O}_{2}$ transport are specific to $\mathrm{Hb}$, thus clearly defining the role of $\mathrm{Hb}$ in bulk $\mathrm{O}_{2}$ transport. Second, $\mathrm{CO}$ poisoning does not interfere with $\mathrm{CO}_{2}$ transport. Finally, blocking $\mathrm{O}_{2}$ transport with $\mathrm{CO}$ is preferable to hemorrhage or other methods of reducing hematocrit, since it has no effect on blood viscosity and thus peripheral resistance.

An early observation of the nonessential role of $\mathrm{Hb}-\mathrm{O}_{2}$ transport in some vertebrates was made by Holeton (1971a), who reported that adult trout were able to survive exposure to $2 \%$ $\mathrm{CO}$ when maintained at cold temperatures $\left(\sim 4^{\circ} \mathrm{C}\right)$. This observation evokes images of the hemoglobinless Antarctic icefish Chaenocephalus aceratus lonnberg. This species survives because it lives at environmental temperatures around $-1^{\circ} \mathrm{C}$. Producing a huge cardiac output with its large heart, this species depends on internal convection of $\mathrm{O}_{2}$ dissolved in solution in the clear plasma (Holeton 1970).

In one of the first uses of CO in a developmental physiology study, Cirotto and Arangi (1989a) exposed chicken embryos to $1 \% \mathrm{CO}$, a level of this gas that effectively eliminated all $\mathrm{Hb}$ $\mathrm{O}_{2}$ transport by blood within $15 \mathrm{~min}$. Not surprisingly, mortality was considerable, but what was surprising was that survival in embryos at days 2, 3, and 5 was $17 \%, 13 \%$, and $8 \%$, respectively (Fig. 3). Indeed, on the basis of these experiments, Cirotto and Arangi (1989b) concluded that there was no hemoglobin-mediated $\mathrm{O}_{2}$ transport for the first $24 \mathrm{~h}$ of convective blood flow in chicken embryos. In larval Xenopus, chronic exposure to $2 \%$ CO not only is not lethal but, surprisingly, has no net effect on growth and development from fertilization up to a larval body mass of $500 \mathrm{mg}$ (Territo and Burggren 1998; Fig. 4). Exposure to 2\% CO in zebra fish larva between 84 and $108 \mathrm{~h}$, a period of vigorous blood circulation, had no effect on $\mathrm{O}_{2}$ consumption (Pelster and Burggren 1996; Fig. 5A). 


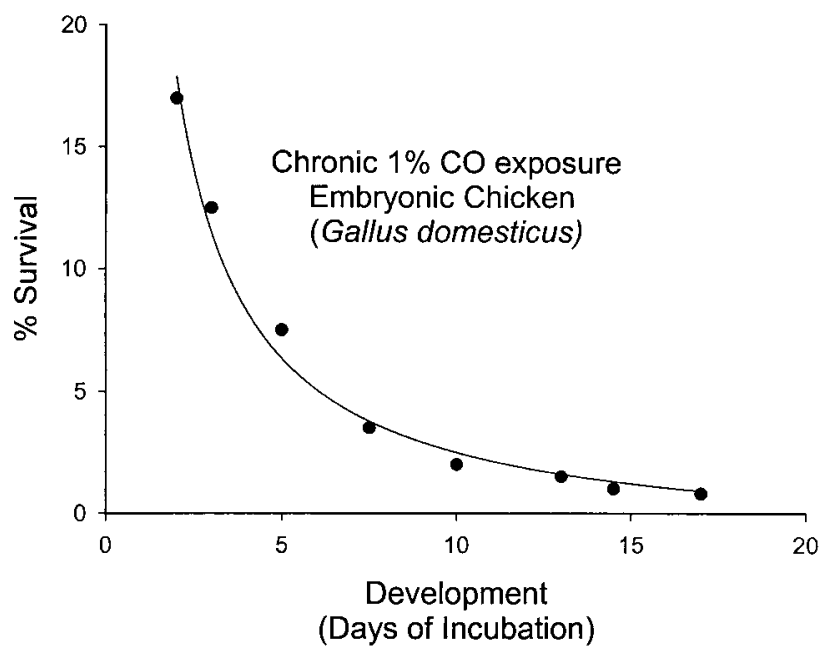

Figure 3. Survival as a function of developmental stage during chronic exposure to $1 \% \mathrm{CO}$ in the chicken embryo. Note that while $\mathrm{CO}$ is increasingly lethal, in early development stages there is significant survival despite elimination of all hemoglobin-based $\mathrm{O}_{2}$ transport. After Cirotto and Arangi (1989a).

The role of $\mathrm{Hb}$ in $\mathrm{O}_{2}$ transport can also be assessed by destruction of the red blood cells through treatment with the hemolytic agent phenylhydrazine. Pelster and Burggren (1996) showed that cell lysis by phenylhydrazine had no affect on whole animal $\dot{M}_{2}$ in zebra fish. They also made ventricular blood pressure measurements in these populations, reasoning that the rate of pressure rise during the initial isometric contraction of the heart should be a highly $\mathrm{O}_{2}$-sensitive barometer of inadequate $\mathrm{O}_{2}$ exchange. As evident in Figure $5 B$, neither phenylhydrazine treatment nor $\mathrm{CO}$ exposure produced a significant change in systolic ventricular blood pressure, nor were there any significant changes in the rate of pressure rise $\Delta \mathrm{P} /$ $\Delta \mathrm{T}$ during isometric ventricular contraction in these zebra fish larvae.

Collectively, these data raise the possibility that bulk transport of $\mathrm{O}_{2}$ through convection of $\mathrm{Hb}-\mathrm{O}_{2}$ in the blood is not an absolute requirement for normal metabolic and physiologic processes in the early embryos of fish, amphibians, and birds (and so presumably all vertebrates?). A minor supporting role of bulk transport of $\mathrm{O}_{2}$ simply dissolved in plasma in animals lacking $\mathrm{Hb}-\mathrm{O}_{2}$ transport cannot be discounted but is unlikely to even partially offset the loss of $\mathrm{Hb}-\mathrm{O}_{2}$ transport in these highly aerobic animals. With these facts in mind, let's consider more draconian experimental approaches.

\section{Disrupting Cardiac Output}

Chemical disruption of $\mathrm{Hb}-\mathrm{O}_{2}$ transport in $\mathrm{CO}$ - or phenylhydrazine-exposed embryos or larvae still leaves open the possibility that like the Antarctic icefish, $\mathrm{O}_{2}$ transport in the plasma may suffice for aerobic metabolic needs. Hence, several studies have used direct intervention with the heart's ability to generate blood flow.

Cardiovascular Mutants. One of the first cardiovascular mutants to receive considerable scrutiny was not in zebra fish or other relatively new animal models but rather in the axolotl Ambystoma mexicanum (Lemanski 1973). The gene $c$ cardiac mutant of this species produces myocardial cells that fail to form organized myofibrils and thus fail to develop a heart beat (see reviews by Fransen and Lemanski 1989; Lemanski et al. 1995). Although almost all attention has been on the cardiac electrophysiology, contractility, and ultrastructure of this mutant, buried in the original articles are the observations that the larvae not only hatch and survive but continue to grow and swim around with a nonbeating heart for up to $2 \mathrm{wk}$.

A wide range of cardiovascular mutants exist for the zebra fish, including those with no heart (e.g., tinman) or those with various heart defects that eliminate the heart's normal blood pumping function (see reviews by Chen and Fishman 1997; Evans 1999; Lohr and Yost 2000; Stainier 2001; also ZFIN, the zebra fish information network, at http://www.grs.nig.ac.jp: 6070). Although the chicken embryo is a stalwart of developmental biology and more specifically developmental physiology, relatively little is known of cardiovascular mutants in this species. There is a mutant chicken $(\mathrm{Ca} / \mathrm{Ca})$ that shows a strong bradycardia but only during the last third of develop-

Larval Clawed Frog (Xenopus laevis)

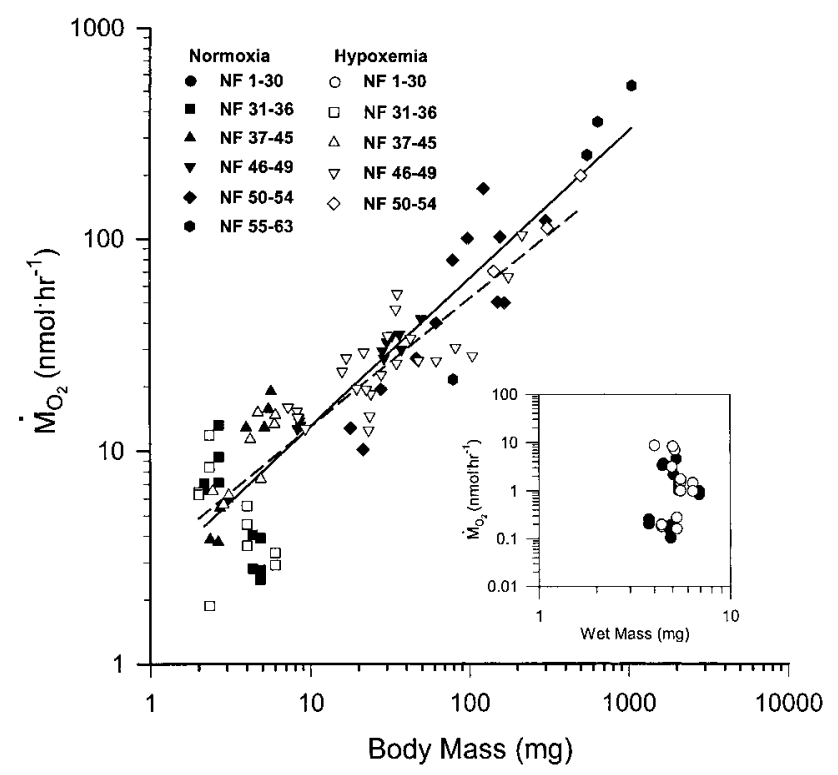

Figure 4. Comparison of $\mathrm{O}_{2}$ consumption in control larval Xenopus and those experiencing hypoxemia due to chronic exposure to $2 \% \mathrm{CO}$. There was no significant difference over a body mass range from 2 $\mathrm{mg}$ to $0.5 \mathrm{~g}$. After Territo and Burggren (1998). 


\section{Larval Zebrafish, Danio rerio}

A

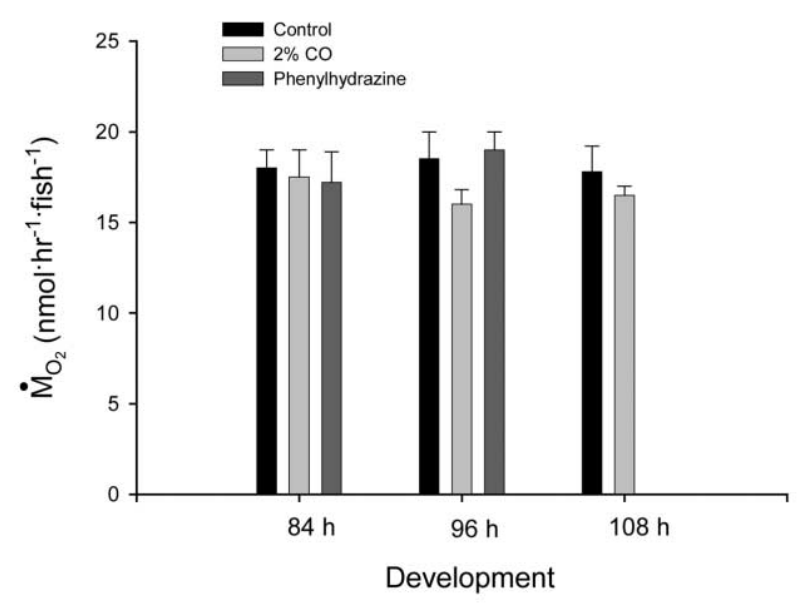

B

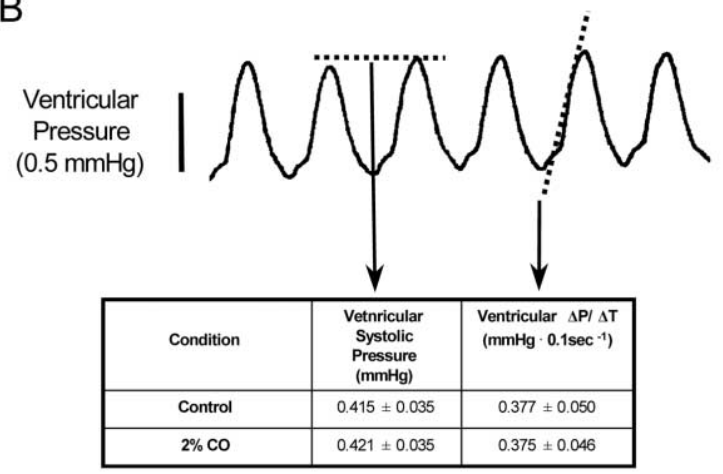

Figure 5. Effects of $\mathrm{CO}$ on the physiology of larval zebra fish Danio rerio. $A, \mathrm{O}_{2}$ consumption before and after exposure to $2 \% \mathrm{CO}$ and to phenylhydrazine, which induces hemolysis. $B$, Ventricular systolic pressure and rate of pressure rise during isometric contraction before and after CO exposure. No significant physiological differences were induced by any of these experimental treatments. After Pelster and Burggren (1996).

ment (Howe et al. 1994). Clearly, several interesting mutants exist that can be exploited in discovering the role of the circulation in the early embryo and in testing hypotheses such as convective synchronotropy.

Heart Ablation. It has long been recognized that removal of the embryonic heart primoridia does not immediately kill lower vertebrate embryos, which may continue to develop for days or weeks (Kemp 1953; Mellish et al. 1994; Grunz 1999). Not only do such heartless animals survive, initially they also thrive. For example, tube heart removal from larval axolotls does not significantly alter their postsurgical $\mathrm{O}_{2}$ consumption when com- pared with sham-operated or wild-type salamander larvae of the same developmental stage (Mellish et al. 1994), suggesting that the heart does not play a necessary role in supporting aerobic metabolism. Interestingly, while heart removal does not affect survival or, apparently, $\mathrm{O}_{2}$ consumption, acardia is not altogether without physiological effect. For example, edema is a common feature of heart myopathies as well as heart absence in embryos/larvae of both zebra fish (Chen et al. 1996; Xu et al. 2002) and Xenopus (Grunz 1999). The presence of the heart is also necessary for proper cervical flexure and craniocervical development in chicken embryos (Männer et al. 1995).

Surgical Conotruncal Ligation. Surgical conotruncal ligation (ligation of the ventricular outflow tract) can be carried out with 10-0 surgical silk in chicken embryos from about day $2+$ until day 5-6 (after which the embryo descends too deeply into the interior of the egg for surgical access). Chicken embryos by day 3-4 have a vigorous circulation, with a rapidly expanding blood volume approaching $50-100 \mu \mathrm{L}$ and a cardiac output of about 20-50 $\mu \mathrm{L} \mathrm{min}^{-1}$ (Romanoff 1967; Tazawa and Hou 1997 for references). Importantly, complete ligation of the outflow tract in either day 3 or day 4 embryos has no effect on the $\mathrm{O}_{2}$ consumption, eye growth, or the degree of cervical flexure increase during a subsequent 4-h postligation period of eye growth and metabolism (Burggren et al. 2000; Fig. 6). Maintenance of $\mathrm{O}_{2}$ consumption under these conditions is especially significant, because earlier studies had shown that early chicken embryos can survive hypoxia and anoxia (e.g., Nelsen 1958; Grabowski 1961; Yamamoto and Noguchi 1964). But for Burggren et al.'s (2000) finding of a maintained $\mathrm{O}_{2}$ consumption during cardiac ligation, it could otherwise have been argued

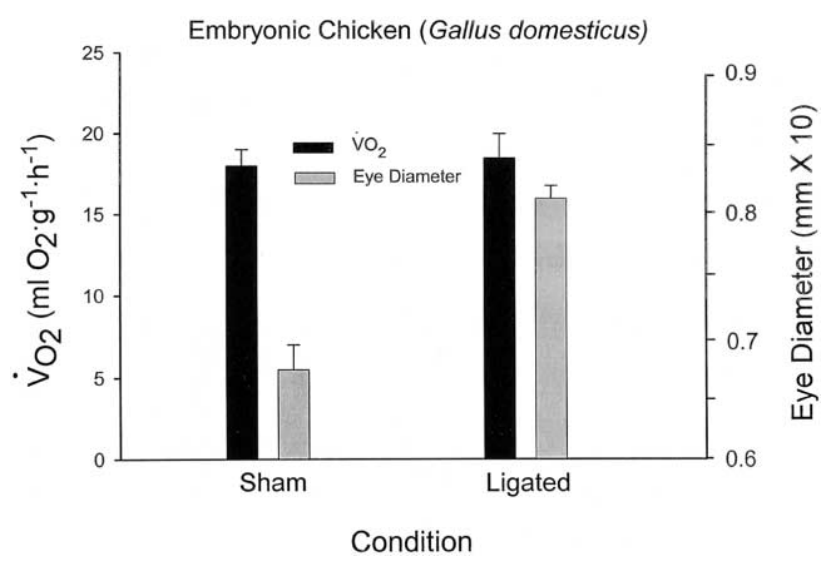

Figure 6. Changes in $\mathrm{O}_{2}$ consumption and eye diameter in 4-d-old chicken embryos before (sham) and 4-5 h after complete conotruncal ligation, which eliminated all cardiac output. As typical for normal development during this period, $\mathrm{O}_{2}$ consumption remained unchanged, and the eyes grew considerably, even after elimination of all cardiac output. After Burggren et al. (2000). 
that perhaps the chicken embryos were simply temporarily switching to anaerobiosis to survive extended anoxia.

That disruption of cardiac output does not disrupt vital physiological and metabolic functions or growth suggest that even in these relatively differentiated chicken embryos, diffusion is adequate for normal exchange of not only respiratory gases but also nutrients and wastes. The normal sources and delivery pathways for the nutrients required for continuing anabolic metabolism will be particularly interesting to study. One can envision experiments along the lines of Sinervo and Huey's (1990) "allometric engineering," using yolk removal or addition from the eggs of zebra fish, chickens, or other developmental models to shed further light on this interesting question.

Conotruncal ligation can be either complete, resulting in a total elimination of cardiac ejection (Burggren et al. 2000), or it can be graded by only partially tightening the suture around the outflow tract, resulting in differing degrees of reduction of cardiac output (e.g., Clark et al. 1984; Tobita et al. 2002). Recently, we have used partial conotruncal ligation to induce chronically up to a 40 -fold range in cardiac output in populations of day 3 and day 4 chicken embryos (W. W. Burggren, S. Khorrami, A. Pinder, and T. Sun, personal communication). Importantly, there was no significant correlation between cardiac output and either eye diameter growth or the density of the chorioallantoic macrovasculature a full $24 \mathrm{~h}$ after partial conotruncal ligation, even at flows a tiny fraction of normal. Perhaps the early chicken embryo simply enjoys an enormous "safety factor" with a cardiovascular design in which the developing heart normally hyperperfuses the embryo's vascular beds by a factor of 10, 20, or higher. This explanation seems quite unlikely because even extreme natural selection rarely produces physiological safety factors greater than two- to fivefold, apparently because of the energetic costs of first creating and then maintaining such large safety factors (Wood and Slater 2001; Diamond 2002). A more probable conclusion is that the heart is beating and generating flow for reasons other than convection.

\section{The Smoking Gun for Prosynchronotropy}

The "just in time" hypothesis of convective synchronotropy as it applies to $\mathrm{O}_{2}$ transport in fishes, amphibians, and birds thus appears to be refuted by the combination of two lines of evidence: the elimination of $\mathrm{Hb}-\mathrm{O}_{2}$ transport without deleterious effects on aerobic metabolism, important physiological functions, or growth, and the elimination of convective bulk transport of $\mathrm{O}_{2}$ in through cardiac mutant models, heart ablation, or contruncal ligation, again without deleterious effects on aerobic metabolism, physiology, or growth. Consequently, the dogma imported from adult physiology-that the vigorous, continuous circulation in the embryo is both necessary and intended for convective bulk material transport-is not well supported. Rather, the alternative hypothesis of prosynchronotropy seems more viable and worthy of further investigation.

\section{Why Does the Heart Beat Early? Morphogenic Prosynchronotropy}

If the embryonic heart does not begin to beat to provide a convective transport function, as in older developmental stages and adults, then why does it begin to beat "early"? There are several feasible possibilities, all relating to morphogenic functions. Let us now consider the hypothesis of morphogenic prosynchronotropy.

\section{Cardiac Morphogenesis}

The role of blood flow in the process of cardiac morphogenesis in chicken embryos has long been debated (Roux 1895; Chapman 1918; Patten 1922; Spitzer 1923). The "flow-molding" hypothesis, in which centrifugal forces generated by blood flowing through the forming heart were presumed responsible for shaping the cardiac chambers, gained early favor (Roux 1895; Spitzer 1923) and was still cited many decades later (e.g., Stalsberg 1970). Perhaps the most definitive test of the flow-molding hypothesis in the tube heart stage was by Manasek and Monroe (1972), who observed that explanted, nonbeating, but otherwise intact embryonic chicken hearts grown from $\mathrm{HH}$ stages 9-12 in vitro still showed typical patterns of cardiac looping. Variations on these experiments have been repeated with similar outcomes on numerous occasions (see review by Manasek 1983; Manning and McLachlan 1990). It is now generally accepted that nonhemodynamic, molecular factors intrinsic to the early embryonic chicken heart are sufficient and necessary for cardiac looping well past those stages at which vigorous blood flow occurs (Icardo 1997; Männer 2000). However, more recent experiments have looked at aspects of cardiac morphogenesis more subtle than the gross anatomy of looping yet still important to cardiac form and function. For example, experiments in early chicken embryos involving explanted hearts suggest that heart beat is involved in the proper formation of the pacemaker and other cardiac conduction tissue (Tucker et al. 1988). Also in chicken embryos, the creation of modified intracardiac blood flow patterns, subaortic ventricular septal defects, semilunar valve anomalies, atrioventricular anomalies, pharyngeal arch artery malformations, left heart hypoplasia, and modified His-Purkinje system development result from unilateral vitelline vein ligation or left atrial ligation (Hogers et al. 1995, 1997; Broekhuizen et al. 1999; Reckova et al. 2003). Not surprisingly, these procedures affect cardiac performance (Tobita and Keller 2000; Ursem et al. 2004). The role of intracardiac blood flow and the accompanying fluid forces as epigenetic factors for heart formation is also being demonstrated in fish embryos (Hove et al. 2003). Finally, blood flows, pressures, and rhythmic distortions generated by the beating embryonic 
heart may play some as yet unknown role in specific molecular programs that ultimately are important to cardiovascular morphogenesis.

Generally, the hypothesis of morphogenic prosynchronotropy draws significant support based on cardiac development. As we will now consider, the role of cardiac hemodynamics and hydraulic forces in blood vessel formation has received much less attention, yet it also bears scrutiny.

\section{Arterial Angiogenesis}

Angiogenesis, the remodeling of existing vessels by sprouting and branching from existing vasculature, is distinguished from vasculogenesis, the formation of new blood vessels from endothelial cords. However, both processes are involved in the development of the circulation (Tomanek and Ratajska 1997; Tomanek and Schatteman 2000; Vargesson 2003). At the cellular level, angiogenesis is well understood. Vascular endothelial cells respond to cyclic shear and stress by secreting vascular endothelial growth factor (VEGF), which, through both paracrine and autocrine pathways, stimulates angiogenesis (for reviews of the role of VEGF in angiogenesis, see Tomanek and Ratajska 1997; Zheng et al. 2001; Ferrara et al. 2003; Vargesson 2003). Fibrobalst growth factor (FGF-2), transforming growth factor (TGF $\beta 1$ ), ephrin, and integrins have all been similarly implicated in vascularization, including the embryonic chicken chorioallantoic membrane and limb bud (Ribatti and Presta 2002).

Despite a vast number of studies identifying the molecular signaling pathways for blood vessel formation and the role of shear/stress in this process, the specific, quantitative role of hemodynamics (i.e., blood flow, blood pressure, and their interaction) in arterial angiogenesis in vertebrate embryos is not well understood. When blood flow is mentioned, it is generally in the context of either providing necessary nutrients or being the outcome of blood vessel formation; seldom is the role of early pulsatile pressure generation directly related to the shear/ strain responses of the growing vasculature. Yet the initial phases of heart beating produce pulsatile arterial flow that may be primarily for arterial angiogenesis rather than convective bulk transport of $\mathrm{O}_{2}$ (i.e., morphogenic prosynchronotropy). In this scenario, early pulsatile flow creates shear/strain on endothelial cells lining sprouting blood vessels (Fig. 7). In response, endothelial cells proliferate under the influence of VEGF and other secreted factors, resulting in the formation of new vessels with through flow of blood subsequently established. I further hypothesize that the rate of blood flow and level of blood pressure influence arterial caliber (not just through stretch of a compliant wall but through actual wall hypertrophy) before the establishment of dynamic regulation by emerging vascular smooth muscle. Indeed, computer simulations and modeling of angiogenesis and vascular branching predict that pressure/flow relationships are important determinants of blood vessel networks (Honda and Yoshizato 1997;
Godde and Kurz 2001). Very recently, Isogai et al. (2003) used time-lapse multiphoton microscopy to determine the role of blood circulation in blood vessel formation in zebra fish embryos. By comparing normal wild type with transgenic silent heart mutants that lacked convective blood flow, they were able to show that circulatory flow dynamics were not required for the gross anatomical patterning of the trunk vasculature. This finding is similar to that reported for day 3 and day 4 chicken embryos (W. W. Burggren, S. Khorrami, A. Pinder, and T. Sun, personal communication), where reductions in cardiac output to as little as one-twentieth of normal had no significant effect on the macrovasculature. However, Isogai et al. (2003) reported that the presence of pulsatile blood flow did appear to play a critical role in the formation of interconnections between the dorsal aorta-derived vascular sprouts and vein-derived secondary sprouts, again supporting the hypothesis of morphogenic prosynchronotropy.

\section{Future Experiments, Insights, and Conclusions}

\section{Future Experiments}

Testing the hypotheses of morphogenic prosynchronotropy for angiogenesis is conceptually straightforward: eliminate or modify blood flow pulsatility and observe subsequent effects, if any, on the growth and caliber of the microvasculature. Conotruncal ligation, pharmacological intervention, or transgenics/mutants could all be used to change the intrinsic pulsatility of the circulation, and thus the magnitude of the shear/strain on the developing vessels as well as the heart itself. The question will then be whether the changes generate corresponding adjustments in cardiac morphogenesis and/or the rate or extent of angiogenesis in various vascular beds of the growing vertebrate embryo (see Isogai et al. 2003.)

Another profitable approach may be to compare the timing of onset of the heart rate in the vertebrate embryo with that of invertebrates having a vigorous circulation but lacking a microcirculation at any stage (e.g., decapod crustaceans). I predict that prosynchronotropy would not occur in such invertebrates because there is no requirement to generate microvasculature at any point in development. Insects such as the tobacco hornworm Manduca sexta that show irregular or patterned cessation of heart beat at different stages of development (see Smits et al. 2000) might also be useful in probing the role of pulsatile blood flow in cardiovascular morphogenesis.

Finally, the studies delineating the role of the embryonic circulation in embryos have tended to be carried out under ideal conditions (fully oxygenated environments, preferred temperatures, etc.). While some vertebrate embryos experience a relatively constant and benign environment (e.g., bird embryos incubated in eggs), for others embryonic life is scratched out in far less hospitable and stable environments (e.g., fish or amphibian species that lay eggs in potentially hypoxic, ephemeral pools). It would be interesting to see how these conclusions 


\section{A. Pulsatile blood pressure exerts shear/strain on endothelial cell lining in region of sprouting vessel tip.}

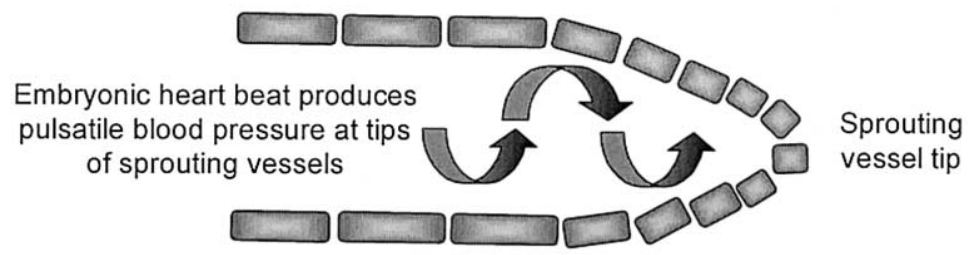

B. Endothelial cells secrete VEGF, FGF-2 and other hormones, stimulating division of nearby cells and proliferation of endothelial cell lining of microvasculature.

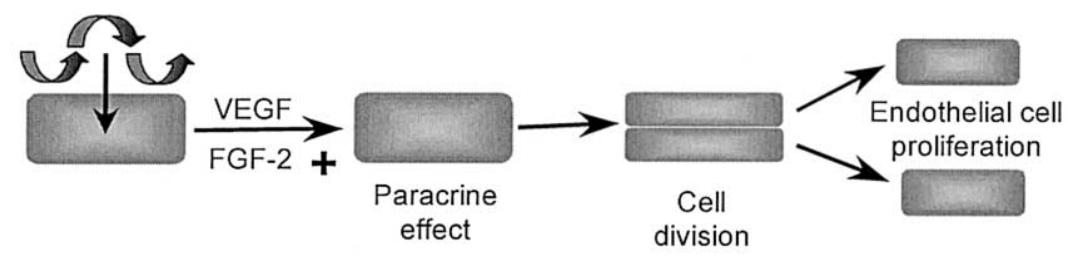

C. Arterial microvasculature proliferates at tip of pulsating "pressure wedge".

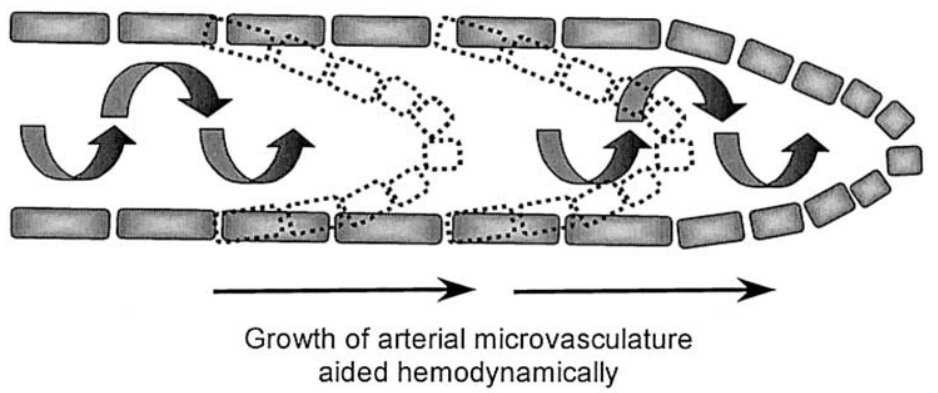

Figure 7. Suggested mechanism by which pulsatile blood pressure in the early embryo facilitates angiogenesis

might be strengthened by repeating and expanding these observations with embryos living at "the edge."

\section{Who Cares about Prosynchronotropy (and Why They Should)}

One might reasonably ask that apart from the drive to carry out so-called curiosity-driven or basic research, who should care about experiments on the embryonic heart and specifically testing of the hypothesis of morphogenic prosynchronotropy? The medical implications may prove profound. Fetal surgery is becoming more and more commonplace and now includes the use of interventional cardiac procedures (Evans et al. 2002; Levi et al. 2003). Both the rate of advancement of sophistication in in utero surgery and the rate at which surgeries are being extended earlier and earlier back in development have accel- erated in just the last few years (Flake 2003). Consequently, it is possible that embryonic surgery along with gene therapy, directed in combination at the earliest stages of development with the greatest self-repair capabilities, may be among the arrows in the quiver of the future pediatric cardiovascular surgeon. Significantly, there may well be cardiovascular bioengineers following the trend to more complex and earlier fetal surgeries who are trying to think far ahead and imagine the construction of microheart lung machines used in support of embryonic surgeries, again borrowing on experience-and dogma-from studies on adults. Yet the basic studies on the developmental physiology of the embryonic heart described in this article provide the insight that circulation may not be nearly so vulnerable to interruptions in convective blood flow. Consequently, a 30-min (or 3-h?) interruption of $\mathrm{O}_{2}$ and nutrient 
supply by the blood-a truly catastrophic event in older developmental stages-may have little or no consequence in the early embryo undergoing surgery. Consequently, microheart lung machines may simply not be needed in the future embryonic surgical theater.

\section{Broader Lessons Learned}

For the Developmental Physiologist. For the developmental physiologist working in the area of cardiovascular development, the data reviewed in this article support the hypothesis we have called morphogenic prosynchronotropy. We suggest that the heart begins to beat and generate convective blood flow to aid in cardiac morphogenesis and related angiogenesis rather than to generate bulk flow of respiratory gases, nutrients, and wastes. It is quite unlikely that the early heart beat is simply an unproductive dress rehearsal. Developmental processes follow parsimonious developmental pathways that conserve hard-won energy passed on to the embryo in the form of maternally supplied nutrients. As a consequence, the heart is unlikely to begin contracting and generating flow and thus expending this precious energy (however small this energy may be as a proportion of the total embryonic energy budget) without the developing organism receiving some tangible dividend. The developmental physiologist's task is to determine precisely why the heart does begin to beat.

For the Developmental Biologist. For biologists working in development generally, a broader lesson may lie in the importance of questioning the validity of our base assumptions. Irrespective of what we conclude to be the ultimate purpose for the onset of embryonic blood flow, the data reviewed here collectively indicate that dogmatic views derived strictly from studies on mature animals can be misleading. That is, the function of organs and tissues (and perhaps even cells and molecules) in developing animals should not be based on adult animals without verification, which would usually require additional experimentation. If the heart does not necessarily start to beat for convective blood flow, why should we automatically assume that the developing kidney first functions to filter plasma, that the developing alimentary tract first shows peristalsis to move its contents, or that the skeletal muscle first contracts to create body movement? Developing animals are not simply very little adults, and increasingly we are discovering qualitative differences in their physiology to accompany the obvious quantitative differences (Burggren 1992, 1995; Burggren and Crossley 2002). While time-honored data from the study of adults provide the developmental physiologist with a wonderful starting point, emerging studies are showing the previously unappreciated richness and uniqueness of embryonic physiology.

A central tenet of the prosynchronotropy hypothesis is that physiological events that consume energy have a discrete purpose. A corollary of this is that energetic considerations drive development. Few developmental biologists would argue this contention, but the typical view of the role of energy in development is that genes and their products drive development in certain directions provided that sufficient energy is available. However, as engineers, mathematicians, and materials scientists learn more about the energetics of artificial self assembling systems (SAMs; see Nolfi and Floreano 2000), and as contemporary science fiction writers show us "what could be" by incorporating SAMs into popular fiction (e.g., Crichton 2002), it appears to be increasingly appropriate to incorporate energetic considerations into the analysis of developing organisms. As one example, some believe that animals may develop the way they do because such patterns of biological macroassembly are simply more thermodynamically favorable (Zotin 1972, 1990; Gladyshev 1996). Future studies of the hypothesis of synchronotropy (perhaps as expanded to other organs and physiological processes) may do well to consider energetic implications more carefully.

In conclusion, this article has attempted to answer the simple question "Why does the embryonic heart beat?" The answer has led to considerations of morphogenesis, energetics, and bioengineering. Perhaps the true lesson learned is that there is no harm in, and that occasionally new insights are gained from, asking seemingly simple questions about developmental physiology.

\section{Acknowledgments}

I am grateful to Ed Dzialowski, Lloyd Fitzpatrick, Sheva Khorrami, and Greta Redd for critiquing this manuscript. In addition, one of the anonymous reviewers, who either dislikes my work or is trying to provide encouragement (I could not tell which), provided one of the most rigorous and thorough reviews I have ever received. Not surprisingly, this article is much the better for it. This article was supported by National Science Foundation operating grant IBN0128043 to W.W.B.

\section{Literature Cited}

Broekhuizen M.L.A., B. Hogers, M.C. De Ruiter, R.E. Poelmann, A.C. Gittenberger-De Groot, and J.W. Wladimiroff. 1999. Altered hemodynamics in chick embryos after extraembryonic venous obstruction. Ultrasound Obstet Gynecol 13:437-445.

Burggren W.W. 1992. The importance of an ontogenetic perspective in physiological studies: amphibian cardiology as a case study. Pp. 235-253 in S.C. Wood, R. Weber, A. Hargens, and R. Millard, eds. Strategies of Physiological Adaptation, Respiration, Circulation and Metabolism. Dekker, New York. - 1995. Central cardiovascular function in amphibians: qualitative influences of phylogeny, ontogeny and seasonality. 
Pp. 175-197 in N. Heisler, ed. Mechanisms of Systemic Regulation. Vol. 1. Respiration and Circulation. Springer, Berlin.

Burggren W.W. and D.A. Crossley II. 2002. Comparative cardiovascular development: improving the conceptual framework. Comp Biochem Physiol 132:661-674.

Burggren W.W. and P. Territo. 1995. Early development of blood oxygen transport. Pp. 45-56 in J. Houston and J. Coates, eds. Hypoxia and Brain. Queen City Printer, Burlington, Vt.

Burggren W.W., S.J. Warburton, and M.D. Slivkoff. 2000. Interruption of cardiac output does not affect short term growth and metabolism in day 3 and 4 chick embryos. J Exp Biol 203:3831-3838.

Chapman W.B. 1918. The effect of the heart-beat upon the development of the vascular system in the chick. Am J Anat 23:175-203.

Chen J.-N. and M.C. Fishman 1997. Genetic dissection of heart development. Pp. 7-17 in W.W. Burggren and B.B. Keller, eds. Development of Cardiovascular Systems: Molecules to Organisms. Cambridge University Press, Cambridge.

Chen J.-N., P. Haffter, J. Odenthal, E. Vogelsang, M. Brand, F.J.M. van Eeden, M. Furutani-Seiki, et al. 1996. Mutations affecting the cardiovascular system and other internal organs in zebrafish. Development 123:293-302.

Cirotto C. and I. Arangi. 1989a. Chick embryo survival under acute carbon monoxide challenges. Comp Biochem Physiol 94:117-123.

- $1989 b$. How do avian embryos breathe? oxygen transport in the blood of early chick embryos. Comp Biochem Physiol 94:607-613.

Clark E.B. and N. Hu. 1990. Hemodynamics of the developing cardiovascular system. Ann N Y Acad Sci 588:41-47.

Clark E.B., N. Hu, and G.C. Rosenquist. 1984. Effect of conotruncal constriction on aortic-mitral valve continuity in the stage 18, 21 and 24 chick embryo. Am J Cardiol 53:324-327.

Crichton M. 2002. Prey. Harper Collins, New York.

Diamond J. 2002. Quantitative evolutionary design. J Physiol 542:337-345.

Evans M.I., M.R. Harrison, A.W. Flake, and M.P. Johnson. 2002. Fetal therapy. Best Pract Res Clin Obstet Gynaecol 16:671683.

Evans S.M. 1999. Vertebrate tinman homologues and cardiac differentiation. Semin Cell Dev Biol 10:73-83.

Feder M. and W.W. Burggren. 1985. Cutaneous gas exchange in vertebrates: design, patterns, control and implications. Biol Rev Camb Philos Soc 60:1-45.

Feder M.E., R.J. Gonzalez, T. Robbins, and C.R. Talbot. 1993. Bulk flow of the medium and cutaneous sodium uptake in frogs: potential significance of sodium and oxygen boundary layers. J Exp Biol 174:235-246.

Ferrara N., H.P. Gerber, and J. LeCouter. 2003. The biology of VEGF and its receptors. Nat Med 9:669-676.
Flake J. 2003. Surgery in the human fetus: the future. J Physiol 547:45-51.

Fransen M.E. and L.F. Lemanski. 1989. Studies of heart development in normal and cardiac lethal mutant axolotls: a review. Scanning Microsc 3:1101-1115;

Fritsche R. and W.W. Burggren. 1996. Developmental responses to hypoxia in larvae of the frog Xenopus laevis. Am J Physiol 271:R912-R917.

Gladyshev G.P. 1996. The thermodynamic direction of biological evolution: the model and the reality. Izv Akad Nauk Ser Biol 4:389-397. (In Russian.)

Godde R. and H. Kurz. 2001. Structural and biophysical simulation of angiogenesis and vascular remodeling. Dev Dyn 220:387-401.

Grabowski C.T. 1961. A quantitative study of the lethal and teratogenic effects of hypoxia on the three-day chicken embryo. Am J Anat 109:15-35.

Grunz H. 1999. Amphibian embryos as a model system for organ engineering: in vitro induction and rescue of the heart anlage. Int J Dev Biol 43:361-364.

Hogers B., M.C. DeRuiter, A.M. Baasten, A.C. Gittenberger-de Groot, and R.E. Poelmann. 1995. Intracardiac blood flow patterns related to the yolk sac circulation of the chick embryo. Circ Res 76:871-877.

Hogers B., M.C. DeRuiter, A.C. Gittenberger-de Groot, and R.E. Poelmann. 1997. Unilateral vitelline vein ligation alters intracardiac blood flow patterns and morphogenesis in the chick embryo. Circ Res 80:473-481.

Holeton G.F. 1970. Oxygen uptake and circulation by a hemoglobinless Antarctic fish (Chaenocephalus aceratus lonnberg) compared with three red-blooded Antarctic fish. Comp Biochem Physiol 34:457-471.

- 1971a. Oxygen uptake and transport by the rainbow trout during exposure to carbon monoxide. J Exp Biol 54: 239-254.

- $1971 b$. Respiratory and circulatory responses of rainbow trout larvae to carbon monoxide and to hypoxia. J Exp Biol 55:683-694.

Honda H. and K. Yoshizato. 1997. Formation of the branching pattern of blood vessels in the wall of the avian yolk sac studied by a computer simulation. Dev Growth Differ 39: 581-589.

Hou P.-C.L. and W.W. Burggren. 1995a. Blood pressures and heart rate during larval development in the anuran amphibian Xenopus laevis. Am J Physiol 269:R1120-R1125.

. 1995b. Cardiac output and peripheral resistance during larval development in the anuran amphibian Xenopus laevis. Am J Physiol 269:R1126-R1132.

Hove J.R., R.W. Koster, A.S. Forouhar, G. Acevedo-Bolton, S.E. Fraser, and M. Gharib. 2003. Intracardiac fluid forces are an essential epigenetic factor for embryonic cardiogenesis. Nature 421:172-177.

Howe R.S., W.W. Burggren, and S.J. Warburton. 1994. Fixed 
patterns of bradycardia during late embryonic development in domestic fowl with $C$ locus pleiotropic mutations. Am J Physiol 268:H56-H60.

Hu N., D. Sedmera, H.H. Yost, and E.B. Clark. 2000. Structure and function of the developing zebrafish heart. Anat Rec 260:148-157.

Icardo J.M. 1997. Morphogenesis of vertebrate hearts. Pp. 114126 in W.W. Burggren and B.B. Keller, eds. Development of Cardiovascular Systems: Molecules to Organisms. Cambridge University Press, Cambridge.

Isogai S., N.D. Lawson, S. Torrealday, M. Horiguchi, and B.M. Weinstein. 2003. Angiogenic network formation in the developing vertebrate trunk. Development 130:5281-5290.

Keller B.B. 1997. Embryonic cardiovascular function, coupling and maturation: a species view. Pp. 65-87 in W.W. Burggren and B.B. Keller, eds. Development of Cardiovascular Systems: Molecules to Organisms. Cambridge University Press, Cambridge.

Kemp N.E. 1953. Morphogenesis and metabolism of amphibian larvae after excision of heart: morphogenesis of heartless tadpoles of Rana pipiens. Anat Rec 117:405-425.

Kimmel P.B. 1992. Adrenergic receptors and the regulation of vascular resistance in bullfrog tadpoles (Rana catesbeiana). J Comp Physiol 162:455-462.

Lemanski L.F. 1973. Morphology of developing heart in cardiac lethal mutant Mexican axolotls, Ambystoma mexicanum. Dev Biol 33:312-333.

Lemanski L.F., S.M. La France, N. Erginel-Unaltuna, E.A. Luque, S.M. Ward, M.E. Fransen, F.J. Mangiacapra, M. Nakatsugawa, S.L. Lemanski, R.B. Capone, et al. 1995. The cardiac mutant gene $\mathrm{c}$ in axolotls: cellular, developmental, and molecular studies. Cell Mol Biol Res 41:293-305.

Levi D.S., J.C. Alejos, and J.W. Moore. 2003. Future of interventional cardiology in pediatrics. Curr Opin Cardiol 18:7990.

Lohr J.L. and H.J. Yost. 2000. Vertebrate model systems in the study of early heart development: Xenopus and zebrafish. Am J Med Genet 7:248-257.

Manasek F.J. 1983. Control of early embryonic heart morphogenesis: a hypothesis. Ciba Found Symp 100:4-19.

Manasek F.J. and R.G. Monroe. 1972. Early cardiac morphogenesis is independent of function. Dev Biol 27:584-588.

Männer J. 2000. Cardiac looping in the chick embryo: a morphological review with special reference to terminological and biomechanical aspects of the looping process. Anat Rec 259:248-262.

Männer J., W. Seidl, and G. Steding. 1995. Formation of the cervical flexure: an experimental study on chick embryos. Acta Anat 152:1-10.

Manning A. and J.C. McLachlan. 1990. Looping of chick embryo hearts in vitro. J Anat 168:257-263.

Mellish J.-A.E, A.W. Pinder, and S.C. Smith. 1994. You've got to have heart ... or do you? Axolotl Newsletter 23:34-38.
Nelsen O.E. 1958. The development of the primitive streak and early chick embryos in relation to low $\mathrm{O}_{2}$ pressure. Growth 22:109-124.

Nolfi S. and D. Floreano. 2000. Evolutionary Robotics: The Biology, Intelligence and Technology of Self-Organizing Machines. MIT Press, Cambridge, Mass.

Patten B.M. 1922. The formation of the cardiac loop in the chick. Am J Anat 30:373-388.

Pelster B. and W.W. Burggren. 1991. Central arterial hemodynamics in larval bullfrogs (Rana catesbeiana): developmental and seasonal influences. Am J Physiol 260:R240R246.

-1996. Disruption of hemoglobin oxygen transport does not impact oxygen-dependent physiological processes in developing embryos of zebrafish (Danio rerio). Circ Res 79: 358-362.

Pelster B., W.W. Burggren, S. Petrou, and I. Wahlqvist. 1993. Developmental changes in the acetylcholine influence on heart muscle of Rana catesbeiana: in situ and in vitro effects. J Exp Zool 267:1-8.

Reckova M., C. Rosengarten, A. deAlmeida, C.P. Stanley, A. Wessels, R.G. Gourdie, R.P. Thompson, and D. Sedmera. 2003. Hemodynamics is a key epigenetic factor in development of the cardiac conduction system. Circ Res 93:77-85.

Ribatti D. and M. Presta. 2002. The role of fibroblast growth factor-2 in the vascularization of the chick embryo chorioallantoic membrane. J Cell Mol Med 6:439-446.

Romanoff A.L. 1967. Biochemistry of the Avian Embryo. Wiley, New York.

Rombough P. 1998. Partitioning of oxygen uptake between the gills and skin in fish larvae: a novel method for estimating cutaneous oxygen uptake. J Exp Biol 201:1763-1769.

- 2002. Gills are needed for ionoregulation before they are needed for $\mathrm{O}_{2}$ uptake in developing zebrafish, Danio rerio. J Exp Biol 205:1787-1794.

Rombough P. and B. Moroz. 1997. The scaling and potential importance of cutaneous and branchial surfaces in respiratory gas exchange in larval and juvenile walleye. J Exp Biol 200:2459-2468.

Roux W. 1895. Gesammelte Abhandlungen über Entwickelungsmechanik der Organismen. 2 vols. Engelmann, Leipzig. Sinervo B. and R.B. Huey. 1990. Allometric engineering: testing the causes of interpopulation differences in performance. Science 248:1106-1109.

Smits A.W., W.W. Burggren, and D. Oliveras. 2000. Developmental changes in in vivo cardiac performance in the moth Manduca sexta. J Exp Biol 203:369-378.

Spitzer A. 1923. Über den Bauplan des normalen und missbildeten Herzens: Versuch einer phylogenetischen Theorie. Virchows Arch Pathol Anat 243:81-272.

Stainier D.Y. 2001. Zebrafish genetics and vertebrate heart formation. Nat Rev Genet 2:39-48.

Stalsberg H. 1970. Development and ultrastructure of the em- 
bryonic heart. II. Mechanism of dextral looping of the embryonic heart. Am J Cardiol 25:265-271.

Talbot C.R. 1992. Regional variation and control of cutaneous gas exchange in bullfrogs. Respir Physiol 89:261-272.

Tazawa H. and P.-C.L. Hou. 1997. Avian cardiovascular development. Pp. 193-210 in W.W. Burggren and B.B. Keller, eds. Development of Cardiovascular Systems: Molecules to Organisms. Cambridge University Press, Cambridge.

Territo P. and J. Altimiras. 2001. Morphometry and estimated bulk oxygen diffusion in larvae of Xenopus laevis under chronic carbon monoxide exposure. J Comp Physiol 171: 145-153.

Territo P. and W.W. Burggren. 1998. Cardio-respiratory ontogeny during chronic carbon monoxide induced hypoxemia in the clawed frog Xenopus laevis. J Exp Biol 201:1461-1472.

Tobita K. and B.B. Keller. 2000. Right and left venrtricular wall deformation patterns in normal and left heart hypoplasia chick embryos. Am J Physiol 279:H959-H969.

Tobita K., E.A. Schroder, J.P. Tinney, J.B. Garrison, and B.B. Keller. 2002. Regional passive ventricular stress-strain relations during development of altered loads in chick embryo. Am J Physiol 282:H2386-H2396.

Tomanek R.J. and A. Ratajska. 1997. Vasculogenesis and angiogenesis in the developing heart. Pp. 35-42 in W.W. Burggren and B.B. Keller, eds. Development of Cardiovascular Systems: Molecules to Organisms. Cambridge University Press, Cambridge.

Tomanek R.J. and G.C. Schatteman. 2000. Angiogenesis: new insights and therapeutic potential. Anat Rec 261:126-135.

Tucker D.C., C. Snider, and W.T. Woods, Jr. 1988. Pacemaker development in embryonic rat heart cultured in oculo. Pediatr Res 23:637-642.

Ursem N.T., S. Stekelenburg-de Vos, J.W. Wladimiroff, R.E.
Poelmann, A.C. Gittenberger-De Groot, N. Hu, and E.B. Clark. 2004. Ventricular diastolic filling characteristics in stage-24 chick embryos after extra-embryonic venous obstruction. J Exp Biol 207:1487-1490.

Vargesson N. 2003. Vascularization of the developing chick limb bud: role of the TGF $\beta$ signaling pathway. J Anat 202:93-103.

Warburton S.J. and R. Fritsche. 2000. Blood pressure control in a larval amphibian, Xenopus laevis. J Exp Biol 203:20472052.

Wells A. and A. Pinder. 1996. The respiratory development of Atlantic salmon. II. Partitioning of oxygen uptake among gills, yolk sac and body surfaces. J Exp Biol 199:2737-2744.

Wells J. 1996. Cutaneous respiration in Octopus vulgaris. J Exp Biol 199:2477-2483.

Wood S.J. and C.R. Slater. 2001. Safety factor at the neuromuscular junction. Prog Neurobiol 64:393-429.

Xu X., S.E. Meiler, T.P. Zhong, M. Mohideen, D.A. Crossley II, W.W. Burggren, and M.C. Fishman. 2002. Cardiomyopathy in zebrafish due to mutation in an alternatively spliced exon of titin. Nat Genet 30:205-209.

Yamamoto S. and Y. Noguchi. 1964. Teratogenic action of hypoxia on the chick embryo. I. Malformations observed in sixday-old embryos. Nippon Juigaku Zasshi 26:181-190.

Zheng W., E.A. Seftor, C.J. Meininger, M.J. Henrix, and R.J. Tomanek. 2001. Mechanisms of coronary angiogenesis in response to stretch: role of VEGF and TGF-beta. Am J Physiol 280:H909-H917; erratum, vol. 280, no. 2.

Zotin A.I. 1972. Thermodynamic aspects of developmental biology. Vol. 5. Monographs in Developmental Biology. Karger, Basel.

- 1990. Thermodynamic Basis of Biological Processes: Physiological Reactions and Adaptations. de Gruyter, New York. 
Copyright of Physiological \& Biochemical Zoology is the property of University of Chicago Press and its content may not be copied or emailed to multiple sites or posted to a listserv without the copyright holder's express written permission. However, users may print, download, or email articles for individual use. 